\title{
Twelve-month-olds communicate helpfully and appropriately for knowledgeable and ignorant partners
}

\author{
Ulf Liszkowski $^{\mathrm{a}, *}$, Malinda Carpenter ${ }^{\mathrm{b}}$, Michael Tomasello ${ }^{\mathrm{b}}$ \\ ${ }^{a}$ Communication Before Language Group, Max-Planck-Institute for Psycholinguistics, Wundtlaan 1, 6525 XD Nijmegen, The Netherlands \\ ${ }^{\mathrm{b}}$ Department of Developmental and Comparative Psychology, Max Planck Institute for Evolutionary Anthropology, Leipzig, Germany
}

\section{A R T I C L E I N F O}

\section{Article history:}

Received 31 August 2007

Revised 7 April 2008

Accepted 29 June 2008

\section{Keywords:}

Infancy

Communication

Social cognition

Knowledge/ignorance

Cooperation

Helping

Informing

Pointing

\begin{abstract}
A B S T R A C T
In the current study we investigated whether 12-month-old infants gesture appropriately for knowledgeable versus ignorant partners, in order to provide them with needed information. In two experiments we found that in response to a searching adult, 12-month-olds pointed more often to an object whose location the adult did not know and thus needed information to find (she had not seen it fall down just previously) than to an object whose location she knew and thus did not need information to find (she had watched it fall down just previously). These results demonstrate that, in contrast to classic views of infant communication, infants' early pointing at 12 months is already premised on an understanding of others' knowledge and ignorance, along with a prosocial motive to help others by providing needed information.
\end{abstract}

(c) 2008 Elsevier B.V. All rights reserved.

\section{Introduction}

Human communication involves complex cognitive and cooperative processes. An important question is whether these complex processes emerge developmentally only with the emergence of language, or before that in prelinguistic communication. Some studies suggest that only verbal children, from around 2-3 years of age, communicate information with an understanding of others' epistemic states (e.g., Dunham, Dunham, \& O'Keefe, 2000; Moore \& D'Entremont, 2001; O'Neill, 1996; Shwe \& Markman, 1997; Wellman \& Bartsch, 1988). And in the classic view of infants' earliest intentional communication before language - as expressed in the pointing gesture at around one year of age - infants communicate only to request things of others imperatively and to obtain emotional reactions declaratively (Bates, Camaioni, \& Volterra, 1975; Gomez, Sarria, \& Tamarit, 1993; Moore \& Corkum,

\footnotetext{
* Corresponding author.

E-mail address: ulf.liszkowski@mpi.nl (U. Liszkowski).
}

1994). This has led some theorists to propose that the complex cognitive processes underlying human communication emerge only with fullblown language during the third year of life (e.g., Carpendale \& Lewis, 2004).

Recently, however, Liszkowski, Carpenter, Striano, and Tomasello (2006) have identified another type of prelinguistic pointing that would seem to require a more sophisticated understanding of the epistemic states of others. From around 12 months of age infants point to inform an adult of things she wants or needs to know. Such informative pointing would seem to depend on an understanding of (1) helping - the other person needs help in attaining her goal; and (2) knowledge-ignorance - the help the other person needs is in the form of information, since she is apparently ignorant about something. The Liszkowski et al. (2006) study was mainly focused on the first of these two preconditions of informative pointing, that is, the understanding of helping. An experimenter (E) first showed infants a demonstration which involved using one of two objects on a substrate, for example using a hole-puncher on a piece of paper. The majority of these 
objects were uninteresting 'adult' objects such as office supplies. Then, both objects were transferred in the same way to different locations out of E's view (this was accomplished in four different ways across trials). After that, E began to search, first non-verbally, then by asking "Where is it?" Infants pointed to inform the adult of the location of the object which E had used before more often than they pointed to the other object which had disappeared simultaneously, and they did this even before E had asked verbally where it was. Infants were not pointing imperatively to obtain the object, as there were very few requestive accompaniments such as whining and reaching or repeated gesturing after $\mathrm{E}$ had retrieved the object. They also were not pointing declaratively to share their excitement about the objects' displacement, as they pointed differentially to one of two simultaneously displaced objects. Instead, infants seemingly were pointing to help the adult find the object she was seeking.

However, from that study it is not clear what infants understood of the adult's knowledge/ignorance when providing information, because there was no direct comparison of conditions in which $\mathrm{E}$ did and did not know about the desired object's location. It is possible that infants simply provided information without considering exactly what $\mathrm{E}$ knew or did not know (or just were responding to a sort of test question, i.e., one that $\mathrm{E}$ already knew the answer to). Further, only one of the two objects was actually used by E (the other object was manipulated, but not actually used). Infants may thus have understood only that the adult needed a specific object to perform the action she wanted to perform - and they knew which object this was and pointed it out for her - but they may not have considered at all in this process anything about the adult's knowledge/ignorance of the location of the object she now needed. There is some evidence in other experimental paradigms that infants this young base their actions on a sensitivity to the knowledge/ignorance of others when interpreting their intentional actions (Tomasello \& Haberl, 2003), and that their visual attention dishabituates when an agent's actions are inconsistent with what he should know (Surian, Caldi, \& Sperber, 2007; for slightly older children see also Onishi \& Baillargeon, 2005). However, to date there is no existing evidence that 12month-olds use an understanding of knowledge/ignorance in formulating overt, helpful communicative acts.

In this study, therefore, we asked directly whether infants' earliest informative pointing at 12 months of age is really based on an understanding of knowledge versus ignorance. In two different experiments E either knew or did not know the location of an object. For example, in Experiment 1, after having used two objects E placed one of them on a slide and watched it go down to the floor, while the other object went down a different slide, without her watching, to a different location on the floor. At test, in response to a searching $\mathrm{E}$, the infant was thus faced with the choice of pointing to an object whose location $\mathrm{E}$ did or did not know already. We predicted that infants would point more often to the 'unknown' object (location unknown to E) than to the 'known' object (location known to $\mathrm{E}$ ), in order to help $\mathrm{E}$ by providing her with information she needed but did not already have. In addition, in the
Liszkowski et al. (2006) study some questions about the helping component were still left open. Specifically, because E only used one of the objects, it is possible that infants were pointing simply in order to make the event happen again (with the one object that had been used previously) rather than to help E attain her goal of obtaining a particular object. In the current studies, therefore, E either used both of the objects or neither of them before she began searching. If infants still pointed helpfully in these situations, this would provide much stronger evidence for infants' understanding of the helping component of informative pointing as well.

\section{Experiment}

\subsection{Method}

\subsubsection{Participants}

Thirty 12-month-old German infants were recruited from a database of parents who had agreed to participate in infant studies. Two were excluded because of fussiness. Thus, 28 infants participated in the final experiment (mean age $12 ; 16$, range $12 ; 00-13 ; 00 ; 16$ boys and 12 girls).

\subsubsection{Set-up and materials}

Fig. 1 shows a photograph of the apparatus. Infants sat on their mother's lap at the short side of a $56 \times 77 \mathrm{~cm}$ child-size table facing E. Attached to the top of the table on E's side was a $28 \times 13 \mathrm{~cm}$ hard foam block. Attached to each side of the block were a long and a short open slide made of cardboard. Different lengths were used to provide variety across repeated trials. The long slides reached down to the floor on each side of E at a distance of approximately $120 \mathrm{~cm}$ from E's midline. Each long slide had a cardboard platform attached to its end on the floor. The back of these platforms had transparent plastic walls but were open on the infants' side. The short slides were positioned in between the long slides and the table (see Fig. 1) and extended $80 \mathrm{~cm}$ to the front and approximately $50 \mathrm{~cm}$ to each side of E's midline. They were mounted on small pillars, $40 \mathrm{~cm}$ from the floor, below the height of the table. The short slides were closed at the ends with transparent walls so that objects that slid down remained there. At the top of each slide was a small barrier which prevented objects which were placed there from automatically sliding down. A hidden trigger could be pulled below the table to inconspicuously lower the barrier and so let the object slide down.

There were four different object pairs, each with two distinct objects. These objects were (i) an ink-stamp and a cellophane tape dispenser, (ii) a small hole-puncher and a correction-tape roller, (iii) a pair of child safety scissors and a glue-stick, and (iv) a staple remover and dispenser of adhesive file markers. Each object pair was used to work on three distinct substrates, thus totaling 12 different substrates. These were things as diverse as a piece of yellow cloth, a box, a paper ball, and aluminum foil.

\subsubsection{Procedure}

During a warm-up period outside the testing room $\mathrm{E}$ engaged in joint attentional play with the infants and 


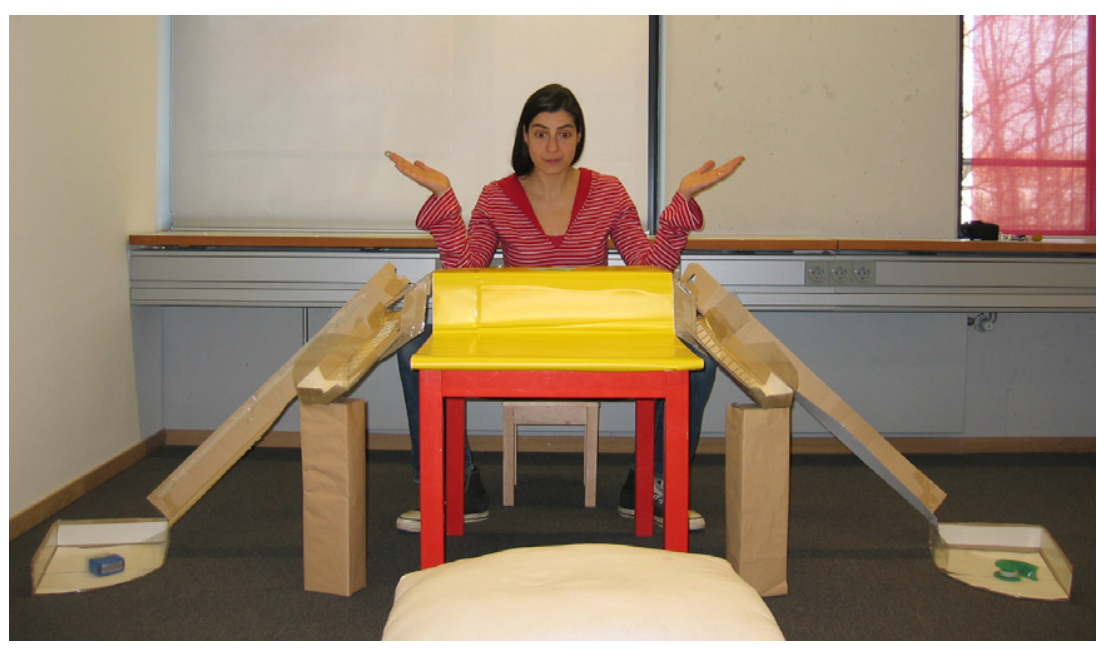

Fig. 1. Experiment 1. A re-enactment of the test situation from the infant's perspective. Target and distractor objects have fallen to the floor on the left and right; a substrate (here: a piece of paper) is on the table in front of $\mathrm{E}$.

assured that they sometimes made eye contact with her and gave or showed her toys. There was no set time limit for the warm-up, but it lasted on average at least $10 \mathrm{~min}$. The experiment consisted of four trials, each of which involved four distinct phases. During all phases E continuously commented to the infant about what she was doing.

In the demonstration phase, E put an object pair on the foam block, showed each object to the infant, and then brought out the first substrate from under the table. She showed the objects to the infant by lifting one object of the pair (e.g., A, counterbalanced across infants) and putting it down again, and then lifting the other object $B$ and putting it to one side (approximately $15 \mathrm{~cm}$ ). Then she used object A on the first substrate (for example, she glued the edges of a piece of cloth together). When she had finished, she drew the infant's attention to the result, expressed satisfaction, and removed the substrate from the table. The same procedure was repeated with object B: E brought out a new substrate, showed the objects again, this time lifting object $B$ at its position on the side and putting it in the middle and lifting object $A$ at its position in the middle and putting it to the other side, and then used object B on the new substrate. Again, E showed the result to the infant, expressed satisfaction, and removed the substrate from the table. If infants turned away from the demonstration, E called their name and drew their attention to her actions.

Next, in the displacement phase, E brought out a third new substrate. She lifted one object (either the one she had used last, positioned in the middle, or the other, positioned at the side, counterbalanced across infants), and placed it next to the barrier at the side, saying: "This one - I'll put it there." Then she lifted the other object and turned with it towards the barrier of the other side (so her back was turned to the first object), saying: "And this one - I'll put it there". At that moment E's attention was fully on the second object. Then, E let that object fall out of her hand onto the slide, attending to it as it slid down the slope, and secretly pulled the hidden trigger on the other side, such that the other object to which $\mathrm{E}$ was not attending also fell down the slide, unnoticed by E. One object (either the one $\mathrm{E}$ was looking at or the one her back was turned to) always fell down about a second earlier than the other, with the result that infants attended to both. The timing of which object fell down first was fully counterbalanced across trials for each infant. The objects remained visible to the infant throughout the test period. The objects slid down the slides from equidistant locations, with the same force (i.e. gravity, since E did not exert additional force on the object she let fall). The noise produced by each of the objects sliding was equally salient. Both objects fell down either the long or the short slides, starting with the long slides and then alternating for the following object pairs.

In the search phase, $\mathrm{E}$ then oriented back to the center of the table, looked at the foam block where she had used the objects in the demonstration phase, and then looked up to the infant. She expressed surprise, raised her hands, palms up, looked around on the table and to the infant, frowned, and said: "Hmm? Where has it gone? Where is it?" During the search $\mathrm{E}$ never looked in the directions of the fallen objects. If the infant pointed to the location of the object which $\mathrm{E}$ had not noticed (the target object), E looked at it, said, "Oh, there!" and retrieved the object. If the infant pointed to the location of the object which $\mathrm{E}$ knew of (the distractor object), E looked at it, said, "Yes, there," and continued her search. If infants did not point to the target, the search terminated after approximately $30 \mathrm{~s}$, when $\mathrm{E}$ found the object herself.

Finally, in the end phase, E used the target object on the new third substrate, showed the result to the infant, expressed satisfaction, and then removed the substrate and the two objects from the table. After this, the trial terminated and $\mathrm{E}$ proceeded immediately to the next trial.

Infants were never given the objects or substrates at any point during the session. If infants were becoming a little fussy during the session, $\mathrm{E}$ engaged them in rolling a ball back and forth across the table after the first two trials. 
This happened only rarely. For most of the time infants simply watched what E was doing.

\subsubsection{Coding and analyses}

Only infants' first point to either the target or distractor was coded in each trial. A student assistant who was blind to the hypothesis of the study coded infants' points when infants extended their arm (either fully or slightly bent) and index-finger or hand in the direction of the target or distractor object. Points to other directions or objects (e.g., the door, the ceiling light, or the back of the room) were not coded. Reliability was assessed in the same way by another student assistant blind to the hypothesis of the study who coded nine infants (32\%). Reliability was excellent. Cohen's Kappa for occurrence/non-occurrence of a first point to either the target or the distractor in each trial was .96 . A reliability check on a different subset of seven infants (25\%) with a naive coder blind to the purpose, hypotheses, and conditions of the study confirmed excellent reliability (Cohen's Kappa $=.89$ ). Eight trials across six infants were excluded due to fussiness (5) or experimenter error (3). Therefore we used as the dependent measure the proportion of trials in which infants pointed first to the target or the distractor. Data did not differ significantly from a normal distribution (Kolmogorov-Smirnov Test, $p=$ n.s.).

\subsection{Results and discussion}

All infants except one pointed at least once across trials. A Cochran's exact test revealed no significant differences in pointing either to the target or to the distractor over the four trials of the session, indicating that there were no learning or fatigue effects.

A planned comparison supported our prediction: infants directed their first point to the object which the adult had not seen disappear significantly more often than to the other object, $t(27)=1.73 ; p=.047,1$-tailed; partial $\eta^{2}=.100$; means $=.37$ vs .26 , respectively $(44 \%$ of the infants pointed more often to the target than to the distractor and 19\% of the infants pointed more often to the distractor than to the target; Binomial test, $p=.071$, 1-tailed), see left panel of Fig. 2. However, a secondary analysis revealed that this effect was relatively small because the temporal sequence of objects falling down (the target fell either first or second, fully counterbalanced across trials) influenced infants' pointing to the target/distractor. That is, a 2(target, distractor) $\times 2$ (first to fall, second to fall) ANOVA revealed a significant interaction, $F(1,27)=12.79, p=.001$; partial $\eta^{2}=.321$, such that the temporal unfolding of events affected infants' subsequent pointing. Therefore we controlled for the temporal sequence and analyzed points to the first and second object separately with regard to differences between target and distractor points, see right panel of Fig. 2. For the second object to fall (mean $=.44$ trials with a point), analyses revealed that infants pointed significantly more to the object when it was the target than when it was the distractor $(t(27)=3.10, p=.004$; partial $\left.\eta^{2}=.262\right)$. However, for the first object to fall, infants pointed overall less (mean $=.19$ trials with a point) and

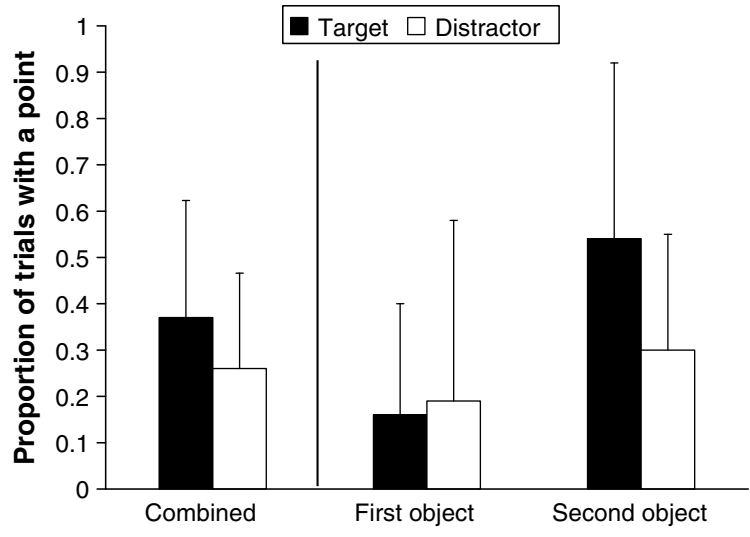

Fig. 2. Experiment 1. Mean proportion of trials with a point to either the target ( $E$ is ignorant) or the distractor ( $E$ is knowledgeable), combined (left panel) and as a function of the objects sliding down first or second (right panel).

approximately equally often irrespective of whether it was the target or distractor $(p>.50)$. The difference between conditions was thus apparent in infants' pointing to the second object.

Post-hoc explanations for this unpredicted interaction effect could be that infants had difficulty recalling what had happened with the first object (because of limited memory capacities or a recency effect), and thus based their pragmatic understanding only on what had happened last, such that this affected whether they then did or did not point to the second object. Perhaps infants did not construe the scenario as a choice between two objects but instead as a choice of pointing or not pointing depending on whether $\mathrm{E}$ had or had not seen the last object. This idea is supported by the fact that when E had seen the last object fall, and so it could not be what she was searching for, infants often did not point at all, to either object (mean $=.54$ trials with no pointing, as compared with .27 trials with no pointing when $\mathrm{E}$ had not seen the last object fall).

Overall, infants thus had a general bias to point to the object that fell down second. With regard to the second object, but not with regard to the first object, however, infants still pointed more often to the object when the adult had not seen it than when she had seen it. Apparently infants realized that if the adult had seen the last object fall she could not possibly be searching for that object (and so they often did not point at all in that case). However, the further and more complex inference that if the adult had seen the last object then she must be searching for the first object may have been too difficult for infants this young. Further, the procedure may have been too complex for 12-month-olds because it required them to rapidly shift attention between two events while also paying attention to $\mathrm{E}$ and interpreting her behavior. To provide a further test of infants' ability to point informatively depending on the knowledge state of the adult we conducted a second experiment in which we eliminated the problems of attentional demands and the timing of the objects falling and in which these more complex inferences were not required. 


\section{Experiment}

In Experiment 2 we used a different method in which no temporal unfolding of events could affect infants' pointing. In this experiment only one object disappeared and $\mathrm{E}$ either knew of its location and so did not need help to find the object, or she was ignorant about its location and so needed information from the infant to find the object. Thus, infants could choose to point or not to point to an object of which E was either knowledgeable or ignorant, instead of having to choose which one of two objects to point to.

In addition, we made several other procedural changes in order to strengthen our interpretation in the case of positive findings. For example, in terms of infants' motivation to help, we omitted the demonstration in which objects were used as tools on substrates. This excludes the possibility that infants would point in anticipation of any particular action demonstrated with the objects, or to see the action again or learn about it. In addition, after $E$ found the objects she then did not use them but instead simply put them away, which excludes the possibility that infants thought they would benefit from whatever E would do with the objects (in fact, even E did not want to do anything in particular with them). The objects were also designed not to afford any specific action schemes and to be of no interest so that no one (including E) would desire them. Finally, E did not intentionally drop any object herself (as she did with the distractor in Experiment 1), thus excluding the possibility that infants would perceive her action as an intentional rejection of the object. This meant that infants would need to draw an inference about E's epistemic state, not her behavioral goal.

We used two similar scenarios which differed only in what $\mathrm{E}$ had and had not seen. Otherwise E behaved identically in each but, depending on what she had and had not seen, different pragmatic construals of the situations were possible. In one scenario E expressed puzzlement because an object disappeared without her knowing its location (and so her puzzlement stemmed from her ignorance about the object's location). In the other scenario $\mathrm{E}$ was puzzled because she saw an object fall but neither had expected this nor knew why it had fallen (and so her puzzlement did not stem from her ignorance about the object's location). Our prediction was that infants would point in the former case, to helpfully provide needed information about the object's location, but not in the latter case because E did not need any help to obtain information about the object's location.

\subsection{Method}

\subsubsection{Participants}

Thirty 12-month-old infants were recruited as in Experiment 1 . Nine infants were excluded because of fussiness in at least half of the trials. Thus, 21 infants participated in the final experiment, 10 in an experimental condition (mean age $12 ; 22 ; 6$ boys and 4 girls) and 11 in a control condition (mean age $12 ; 20 ; 6$ boys and 5 girls).

\subsubsection{Materials and design}

Fig. 3 shows the set-up of this experiment. Infants sat on their parent's lap at a child-size table facing the experimenter (E). The bottom of the infant's side of the table was occluded with wallpaper, and a box was put between the table and the infant's chair to increase the distance between the infant and the table. A $30 \times 5 \times 15 \mathrm{~cm}$ long hard foam bar was attached along the vertical midline of the table. The bar supported an opened, cardboard office folder $(61 \times 32 \mathrm{~cm})$ on its spine with the cover facing up. Cardboard walls were attached to the sides of the table to support the left and right edges of the folder. The folder thus formed a parallel plane to the table, about $15 \mathrm{~cm}$ above it. The cardboard walls on the edges could be secretly tipped over toward the bar so that the sides of the opened folder would flap down on to the table and form an inclined plane to either side. On the infant's side a curtain was attached to the long edge of the opened folder which occluded this mechanism. Objects could slide down the slope of the inclined folder along a ruler which was glued to its top, and fall to the floor at a predetermined location on each side of the table. These locations were padded with folded white blankets on which the objects could softly fall without emitting a loud noise. On each side of E's chair, about $60 \mathrm{~cm}$ away, was a small chest of drawers. Four cameras were fed into a quad splitter which recorded $\mathrm{E}$, the infant from two sides, and the overall scene.
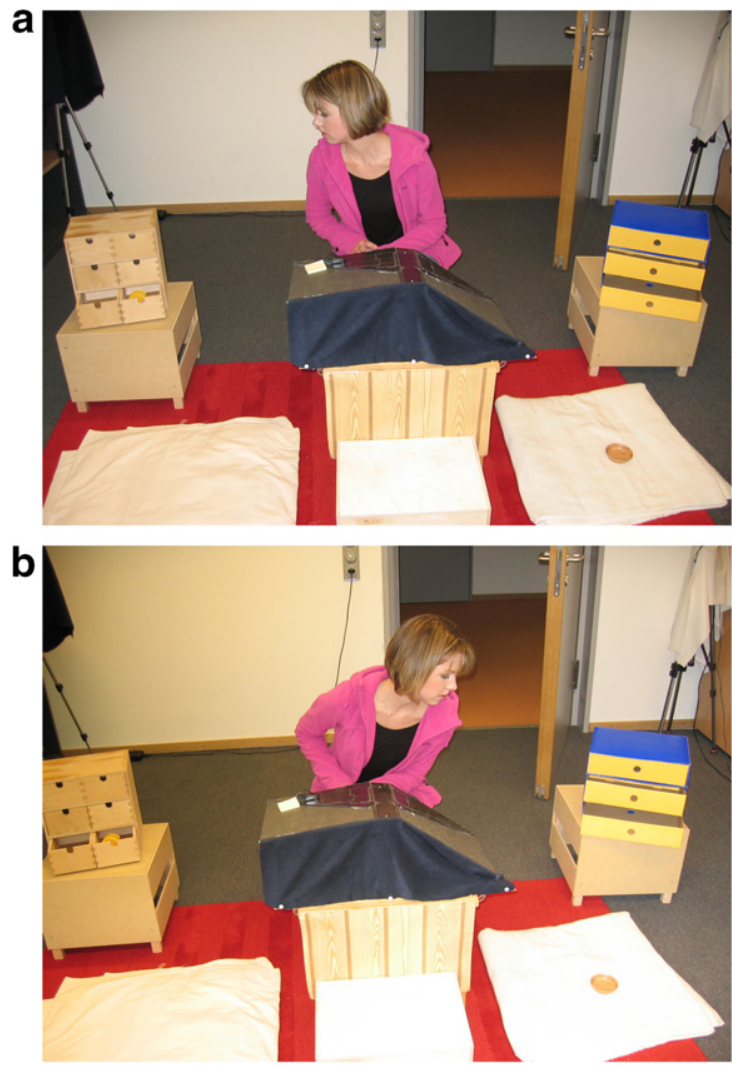

Fig. 3. Experiment 2. A re-enactment of (a) the experimental condition and (b) the control condition before the test. 
There were four sets of five objects. All objects were uninteresting office supplies or objects which did not afford any interesting actions for infants. For example, one set consisted of a rectangular piece of foam, a small cardboard box, a sales slip roll, a pink sock, and a solid rectangular piece of plastic, see Fig. 4 . Each set had one target object. Across sets, these were a black solid rectangular piece of plastic, a small brown flowerpot saucer, a piece of green Styrofoam, and a folded pair of black socks.

\subsubsection{Procedure}

The warm-up procedure was as in Experiment 1. The experiment consisted of four trials. On each trial, E put a set of objects on the folder (with a fixed order of object sets). In the first trial $\mathrm{E}$ called the infant's attention, looked at all the objects and said: "Hm..., what do we have here?" She then lifted the first object and said: "Look at this one! I'll put it away. In here". She turned to one side (counterbalanced) and put the object into an open drawer next to her. Then she looked around on the folder, touched the second object, said, "This one is not so great. I'll put it here," and brushed it away mildly to the side of the folder. Both steps were repeated for the next two objects. The steps alternated within a trial and the beginning (i.e., putting it in the drawer vs. to the side of the folder first) alternated across trials. At the end of this, two objects were thus put away into the drawer, two objects were lying on the side of the folder, and one object was still in the middle. At this moment, E surreptitiously made the cardboard wall under the other side of the folder tip over, without the child being able to see it. The fifth (target) object fell down the inclined plane onto the blanket on the floor.

In the experimental condition (see Fig. 3a, while the object fell, $\mathrm{E}$ looked to the opposite side and so could not see the object fall. She maintained her head orientation to the side for about $3 \mathrm{~s}$. She neutrally uttered, "Hm. Aha," to attract infants' attention to her head orientation. In the control condition (see Fig. 3b, in contrast, E watched the object as it fell and maintained her focus on the object on the ground for the same amount of time and with the same utterances as in the experimental condition. Thus, the only

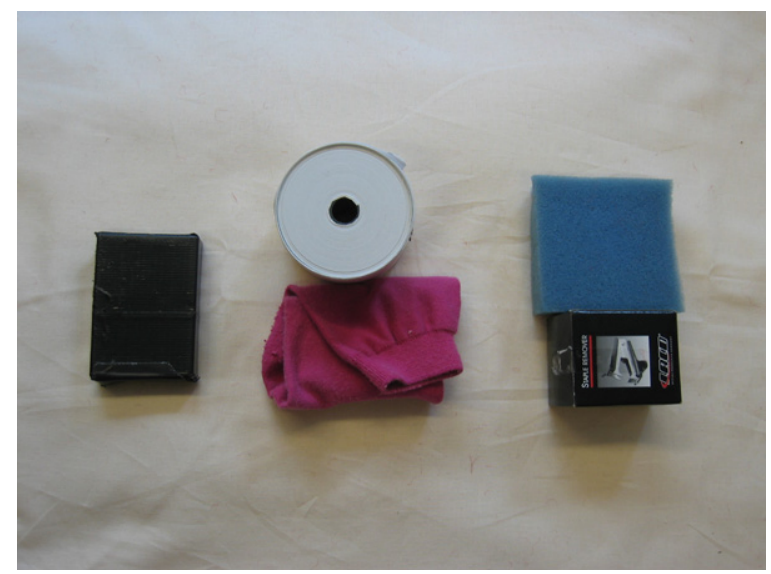

Fig. 4. Experiment 2. One of the four sets of objects. The leftmost object is the target object. difference between conditions was whether $\mathrm{E}$ saw the object fall and thus did or did not know about the object's location.

In the test phase, E then turned back and looked at the folder, uttered "Hm...?", looked at the infant, and looked back at the folder. She briefly lifted the loose, hanging side of the folder and expressed mild puzzlement. In the first part of the test phase (approximately $15 \mathrm{~s}$ ) she said in a predetermined and timed but natural sequence something like "hm...huh...that's strange...well" (in German: "nanu. . . na sowas. . .das ist ja komisch. . . sowas"). Then, to give infants more time to respond, while still keeping things natural, in the second part (approximately $15 \mathrm{~s}$ ) she added questions to her puzzled expressions, again in a predetermined and timed but natural sequence. The first question in both conditions started with the German word 'where': "Wo ist das denn?" (English: "Where is it?") in the experimental condition and "Wo gibt's denn sowas?" (English: "Where [=how] can that happen?") in the control condition. Then other similar questions followed, with their timing and number matched across conditions. The pragmatics of both conditions could thus be construed as E either searching for the object that was now no longer on the folder (experimental) or as $\mathrm{E}$ being puzzled that the object fell down, but not being ignorant about its location (control). If infants pointed to the target object, $\mathrm{E}$ then said neutrally "Ah" (experimental) or "yes" (control), "there it is," and picked up the object from the floor. She then put it together with the other objects from the folder away under the table and proceeded to the next trial.

As in Experiment 1, infants were never given any of the objects. If infants became fussy or restless, E tried to comfort them and played with them with a doll. Nevertheless, a number of infants were too fussy or bored to be tested, presumably because nothing interesting happened in the procedure apart from $\mathrm{E}$ sorting her things for no apparent reason.

\subsubsection{Coding and analyses}

Coding of points in the first and second test phase was done as in Experiment 1. In addition, in order to look for potential request behaviors, we separately coded reaches when infants leaned forward with their bodies and arm(s) toward the direction of the object with wide open hands and/or a grasping motion. Furthermore, in order to check whether infants were equally aware of the object's location in both conditions, we coded whether infants looked at the object during its disappearance and during the test phase. Reliability on a subset of three infants in each condition (27-30\%) for the first and second test phase was excellent for points (100\% agreement) and for looks to the object (Cohen's Kappa $=.77$ ). A reliability check on pointing in a different subset of three infants in each condition with a naive coder blind to the purpose, hypotheses, and conditions of the study confirmed excellent reliability (Cohen's Kappa $=.83$ ). In the experimental condition, pointing data were normally distributed. In the control condition, however, the pointing data had many zeros and deviated significantly from a normal distribution (Kolmogorov-Smirnov Test, $p=.029$ ). Therefore, we used non-parametric tests. 


\subsection{Results}

Infants in the experimental condition pointed in significantly more trials than infants in the control condition (17 vs. 3 points; mean proportion of trials with a point: experimental $=.47$, control $=.08$; Mann-Whitney test, $p=.025$; see Fig. 5). The pattern was similar when analyzing only the points of the first part of the test phase before $\mathrm{E}$ had asked a single question (experimental $=.36[S D=.33]$, control $=.08[S D=.14]$; Mann-Whitney test, $p=.042$ ).

In the experimental condition $70 \%$ of the infants pointed at least once, whereas in the control condition only $27 \%$ of the infants pointed (each only once; Fisher's exact test, 1 -tailed, $p=.063$ ). The pattern was similar when analyzing only infants' first trial, in which they could not already have learned anything about the procedure: In the experimental condition $63 \%$ of the infants pointed, whereas in the control condition only $11 \%$ of the infants pointed (Fisher's exact test, 1-tailed, $p=.043$ ). With regard to infants' individual performance, $50 \%$ of the infants in the experimental condition pointed on more than half the trials whereas none of the infants did this in the control condition (Fisher's exact test, $p=.012$ ).

The majority of points (70\%) were index-finger points and occurred spontaneously within the first part of the test phase (80\%). There was no evidence that infants construed the context as a request context since only three reaches were observed (by one infant in the experimental condition and two infants in the control condition; these were not included in the analyses). Further, infants were equally aware of the object's location in both conditions: All infants saw the object fall down during the disappearance phase, except for two infants in the experimental condition (each on one trial) who then detected the object in the test phase (one infant then pointed to it and one did not).

\subsection{General discussion}

This study demonstrates that already by age 12 months, before they have acquired language, infants point informa-

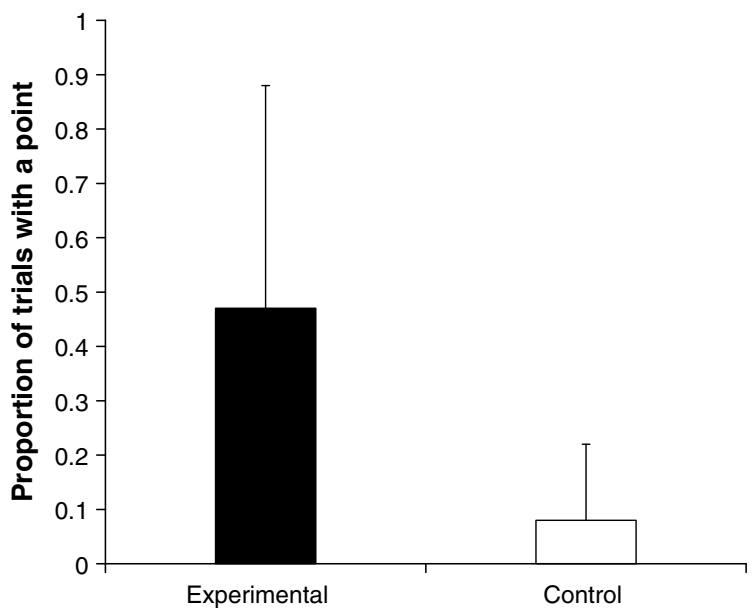

Fig. 5. Experiment 2. Mean proportion of trials with a point in the experimental ( $\mathrm{E}$ is ignorant) and control ( $\mathrm{E}$ is knowledgeable) conditions. tively, communicating appropriately for knowledgeable and ignorant adults. They do this with the prosocial motive to help others without direct benefit for the self. At the same time, the study rules out several possible alternative explanations.

First, infants chose between pointing to an object which the adult did or did not know about. The findings thus eliminate the possibility that infants simply provided information in response to test questions without considering E's epistemic state of ignorance. Instead, the study shows that it is the recipient's psychological relation to an object - her ignorance about its location and her intention to overcome this ignorance - that elicits infants' informative pointing. It is important to note that in both experiments at test E was not looking at the objects. Thus, to point correctly infants had to draw an inference about E's epistemic state of knowledge/ignorance, that is, what she had and had not seen before - they could not simply point on the basis of what she currently could or could not see (or simpler cues like body orientation) at that moment.

Second, the procedures of both experiments exclude the possibility that infants only pointed out or requested a next step in E's action sequences. In Experiment 1, in the demonstration phase, both objects were treated equally and there was a new substrate in the test phase such that no particular next action could be inferred from the physical context alone. Further, in Experiment 2, there was no action demonstration at all, nor did E subsequently conduct any action with the object, so no action or action effect could be anticipated or requested. There was also nothing of particular interest which infants might have wanted to share, or obtain, or learn about, excluding the possibility that infants only pointed for such reasons (in any case, it would be difficult to explain why infants pointed for these alternative reasons in one but not in the other condition in Experiment 2).

Instead, the current study directly compared infants' responses to an object that $\mathrm{E}$ needed help finding with their responses to an object she did not need help finding. The results show that it is the recipient's goal to find the object and her need for help in finding it - and not the referent per se, nor the infant's desire to obtain it - that motivates infants to point in this context. This study thus provides the strongest experimental evidence to date that infants already help others at this early, still prelinguistic age by freely providing information for others. It is also important to note that in Experiment 1 infants freely chose whether to respond (as reflected in the overall response rate of $63 \%$ ) and were thus not simply confronted with a forced choice to react. This was even more so in Experiment 2, in which the vast majority of points were initiated already before $\mathrm{E}$ asked the infant for anything. Note also that in Experiment 2 the search phases were matched for the timing and numbers of questions, and the questions in both conditions started with the same question word, making syntactic or semantic influences very unlikely. Most crucially, however, the difference between conditions was significant already before any question had been asked.

With regard to helping, informative pointing is a special case. Helping by informing inextricably involves both an understanding of others' goals and an understanding of 
others' ignorance. Once the recipient's goal/motivational state is understood, helping can occur in the form of various behavioral means (e.g., by giving the object or physically enabling the other to take it), but only if one understands a person's ignorance too, can informing become a relevant means for helping. Informative pointing thus involves not physical assistance to change a world state, but instead the offer of information to change a mental state. The need to intervene arises from the recipient's difficulties in finding an object (her ignorance), rather than from an unsuccessful action attempt as, for example, in Warneken and Tomasello's (2007) study of more instrumental helping. In the current study both the need for help and the help itself were expressed on a mental level, with regard to E's epistemic state. The adult did not express her need for help by performing physical, object-directed actions such as reaching or other unsuccessful attempts - she either knew or did not know about the objects' location. And infants did not physically give an object or complete an action for the adult - they simply provided her with the relevant information she needed. In this sense informative pointing may even be seen as a first step toward human forms of teaching and instructing, which complement infants' capacity for cultural learning with the ability to actively transmit relevant knowledge.

In summary, the current study demonstrates in prelinguistic infants the presence of complex cognitive communicative processes previously attributed only to older, 2- to 3 -year-old children. The study provides experimental evidence for both a mentalistic and prosocial interpretation of infant pointing (see Tomasello, Carpenter, \& Liszkowski, 2007, for further evidence of this interpretation). Several recent studies have provided independent converging evidence with other paradigms that young 1-year-olds may already have the social-cognitive and motivational prerequisites for informative pointing: They understand something about others' goals and intentions (e.g., Behne, Carpenter, Call, \& Tomasello, 2005; Schwier, van Maanen, Carpenter, \& Tomasello, 2006), others' knowledge (e.g., Liszkowski, Carpenter, \& Tomasello, 2007; Onishi \& Baillargeon, 2005; Surian et al., 2007; Tomasello \& Haberl, 2003), and they have and understand prosocial motives for interacting with others (Kuhlmeier, Wynn, \& Bloom, 2003; Liszkowski, Carpenter, Henning, Striano, \& Tomasello, 2004; Warneken \& Tomasello, 2007). This study demonstrates that 12-month-olds act on the basis of these social-cognitive and motivational abilities and actively help others by communicating needed information prosocially in communicative and cooperative ways. These early communication skills, which include an understanding of others' epistemic states, goals, and a motive to benefit others, provide a strong ontogenetic basis for the development of uniquely human language, social cognition, and complex shared cooperative activities upon which human culture is predicated.

\section{Acknowledgements}

Thanks to Elena Rossi, Jana Hausbek, Konstanze Albrecht, Marie Schäfer, Jana Reifegerste, Anika Burmeister, Nina Brosche, and Manja Teich for coding and helping with the data collection.

\section{References}

Bates, E., Camaioni, L., \& Volterra, V. (1975). The acquisition of performatives prior to speech. Merrill-Palmer Quarterly, 21, 205-226.

Behne, T., Carpenter, M., Call, J., \& Tomasello, M. (2005). Unwilling versus unable: Infants' understanding of intentional action. Developmental Psychology, 41, 328-337.

Carpendale, J., \& Lewis, C. (2004). Constructing an understanding of mind: The development of children's social understanding within social interaction. Behavioral and Brain Sciences, 27, 96-97.

Dunham, F., Dunham, F., \& O'Keefe, C. (2000). Two-year-olds' sensitivity to a parent's knowledge state: Mind reading or contextual cues? British Journal of Developmental Psychology, 18, 519-532.

Gomez, J. C., Sarria, E., \& Tamarit, J. (1993). The comparative study of early communication and theories of mind: Ontogeny, phylogeny, and pathology. In S. Baron-Cohen, H. Tager-Flusberg, \& D. J. Cohen (Eds.), Understanding other minds: Perspectives from autism (pp. 397-426). New York: Oxford University Press.

Kuhlmeier, V., Wynn, K., \& Bloom, P. (2003). Attribution of dispositional states by 12-month-olds. Psychological Science, 14, 402-408.

Liszkowski, U., Carpenter, M., Henning, A., Striano, T., \& Tomasello, M. (2004). Twelve-month-olds point to share attention and interest. Developmental Science, 7, 297-307.

Liszkowski, U., Carpenter, M., Striano, T., \& Tomasello, M. (2006). Twelveand 18-month-olds point to provide information. Journal of Cognition and Development, 7, 173-187.

Liszkowski, U., Carpenter, M., \& Tomasello, M. (2007). Pointing out new news, old news, and absent referents at 12 months. Developmental Science, 10, F1-F7.

Moore, C., \& D'Entremont, B. (2001). Developmental changes in pointing as a function of attentional focus. Journal of Cognition $\mathcal{E}$ Development, 2, 109-129.

Moore, C., \& Corkum, V. (1994). Social understanding at the end of the first year of life. Developmental Review, 14, 349-372.

O'Neill, D. K. (1996). Two-year-old children's sensitivity to a parent's knowledge state when making requests. Child Development, 67, 659-677.

Onishi, K. H., \& Baillargeon, R. (2005). Do 15-month-old infants understand false beliefs? Science, 308, 255-258.

Shwe, H. I., \& Markman, E. M. (1997). Young children's appreciation of the mental impact of their communicative signals. Developmental Psychology, 33, 630-636.

Schwier, C., van Maanen, C., Carpenter, M., \& Tomasello, M. (2006). Rational imitation in 12-month-old infants. Infancy, 10, 303-311.

Surian, L., Caldi, S., \& Sperber, D. (2007). Attribution of beliefs by 13month-old infants. Psychological Science, 18, 580-586.

Tomasello, M., Carpenter, M., \& Liszkowski, U. (2007). A new look at infant pointing. Child Development, 78, 705-722.

Tomasello, M., \& Haberl, K. (2003). Understanding attention: 12- and 18month-olds know what's new for other persons. Developmental Psychology, 39, 906-912.

Warneken, F., \& Tomasello, M. (2007). Helping and cooperation at 14 months of age. Infancy, 11, 271-294.

Wellman, H. M., \& Bartsch, K. (1988). Young children's reasoning about beliefs. Cognition, 30, 239-277. 